\title{
Mediterranean Spotted Fever Complicated with Thrombosis of the Left Central Retinal Vein: A Case Report and Literature Review
}

\author{
Ermira Muco ${ }^{*}$, Arta Kushi ${ }^{1}$, Neada Hoxha ${ }^{1}$, Anila Monka ${ }^{2}$, Ali Tonuzi ${ }^{2}$, Majlinda Kota ${ }^{3}$, \\ Artan Bego ${ }^{3}$, Dhimiter Kraja ${ }^{1}$ \\ ${ }^{1}$ Department of Infectious Diseases, University Hospital Center "Mother Tereza”, Tirana, Albania \\ ${ }^{2}$ Department of Ophthalmology, University Hospital Center "Mother Tereza”, Tirana, Albania \\ ${ }^{3}$ Institute of Public Health, Tirana, Albania \\ Email: *ermiramuco@yahoo.com
}

How to cite this paper: Muco, E., Kushi, A., Hoxha, N., Monka, A., Tonuzi, A., Kota, M., Bego, A. and Kraja, D. (2018) Mediterranean Spotted Fever Complicated with Thrombosis of the Left Central Retinal Vein: A Case Report and Literature Review. Journal of Biosciences and Medicines, 6, 69-75.

https://doi.org/10.4236/jbm.2018.64005

Received: March 21, 2018

Accepted: April 21, 2018

Published: April 24, 2018

Copyright (ㅇ 2018 by authors and Scientific Research Publishing Inc. This work is licensed under the Creative Commons Attribution International License (CC BY 4.0).

http://creativecommons.org/licenses/by/4.0/

\section{(c) (i) Open Access}

\begin{abstract}
We describe a case of Mediterranean spotted fever complicated with thrombosis of the left central retinal vein. A 41-year-old woman patient living in the city Scodra was referred to our hospital in October 2017 for high fever $40^{\circ} \mathrm{C}$, muscular and articular pains, severe headache, maculopapular rash, chills, photophobia and visual loss in his left eye. Ocular examination showed vision acuity: OD 8/10, OS 2/10. Funduscopic examination complemented with fluorescein angiography showed: optic nerve papilla with clear contours, diffuse hemorrhages in the contest off retinal vein thrombosis, white retinal lesions, vascular sheathing and macular cystoids edema. $R$. conorii antibodies were identified by ELISA anti Rickettsia conorii IgM, IgG and Weil-Felix Ox-19 test. Investigation of other infective agents and the immunological panel were negative. After treatment with doxycycline $200 \mathrm{mg} /$ day for 10 days vision acuity was OD: 8/10 OS: 6/10; FO: There are less hemorrhages in fluorescein angiograph and OCT showed a reduced macular cystoids edema. Mediterranean spotted fever should be considered in the differential diagnosis of a patient who presents with an acute febrile disease accompanied by maculopapular rash especially in the seasons of spring, summer or autumn.
\end{abstract}

\section{Keywords}

Mediterranean Spotted Fever, Rickettsia conorii, Thrombosis,

Central Retinal Vein

\section{Introduction}

Rickettsia conorii, the most widespread rickettsia of the spotted fever group, is 
the etiological agent of Mediterranean spotted fever (MSF) in humans, known as Boutonneuse fever. The brown dog tick, Rhipicephalus sanguineus is the prevalent vector. MSF is endemic to the Mediterranean area, including northern Africa and southern Europe. It is suspected to be endemic in Slovenia, Albania, Ukraine, Georgia and Zimbabwe [1]. The classic diagnostic triad is characterized by fever, maculopapular rash (involving palms and soles), inoculation scars or tache noir [2]. Most patients with MSF present with a "tache noîr", a small crust surrounded by a violet erythemic halo, which represents the typical appearance of the MSF entrance site caused by the tick bite [3]. Mild vitritis, retinal vasculitis, optic disc staining, white retinal lesions, retinal hemorrhages, and multiple hypofluorescent choroidal dots are the manifestations of MSF [4]. The exact pathogenesis of the thrombotic occlusion of the central retinal vein is not known. Various local and systemic factors play a role in the pathological closure of the central retinal vein [5]. Angiotropism with multiplication in the host endothelial cells is the predominant feature leading to cell necrosis, thrombosis, and organ dysfunction [6]. On the other hand, rickettsial organisms are known to invade small blood vessels causing endothelial injury and tissue necrosis. In addition, glutamic acid which is found abundantly in retina is known to be involved in the pathogenicity of rickettsia [7]. Due to marked angiotropism of rickettsial organisms, it has been reported that the white retinal lesions in rickettsial retinitis could be a result of multiplication of organisms in inner retina or alternatively due to immune complex deposition along retinal vessels [8]. It is imperative to start oral antibiotics such as doxycycline since it is effective and achieves good intracellular levels [9].

\section{Case Report}

A 41-year-old woman presented in October with a 5-day history of high fever $40^{\circ} \mathrm{C}$, muscular and articular pains, severe headache, chills and photophobia. Three days after the onset of fever the patient started to have maculopapular rash over face, anterior trunk, back, upper extremities that involving also the palms of the hands and the soles of the feet. The patient reported decreased visual loss in her left eye on the five day of the beginning of the clinic. Our patient has a contact with dogs and patients reported tick bites six days before the start of the clinic. The patient came from Scodra (Table 1).

General examination of the patient showed pharyngitis, conjunctivitis and a black eschar in the region of the left arm (Figure 1). Diabetes, autoimmune disease, cardiovascular disease, thyroid disorder, peptic ulcer and thrombophilia causes were excluded. Central nervous system examination was normal. No smoking, no alcohol consumption and she is not considered obese.

Abdominal echography: liver and spleen sizes were respectively 168 and 135 $\mathrm{mm}$. Chest X-ray findings included atypical pneumonia. Cranial and abdominal CT scan were performed which were normal. Electrocardiogram and echocardiography were normal. Laboratory examination resulted: leucocytes $4.3 \times$ 
Table 1. Epidemiological manifestations, clinical signs and symptoms of Mediterranean spotted fever complicated with thrombosis of the left central retinal vein to our patient.

\begin{tabular}{cc}
\hline Epidemiological and clinical data & Case \\
\hline Patient's age & 41 years old \\
Gender & Female \\
City & Scodra (Mediterranean climate) \\
The season of occurrence of the disease & Autumn \\
Contact with domestic animals & Contact with dogs \\
Tick bites & Yes \\
Duration of symptoms & 5 days \\
Symptoms and signs & $\begin{array}{c}\text { Fever, muscular and articular pains, severe } \\
\text { headache, chills, photophobia, visual loss } \\
\text { in his left eye, conjunctivitis, pharyngitis, } \\
\text { a maculopapular rash }\end{array}$ \\
\hline
\end{tabular}

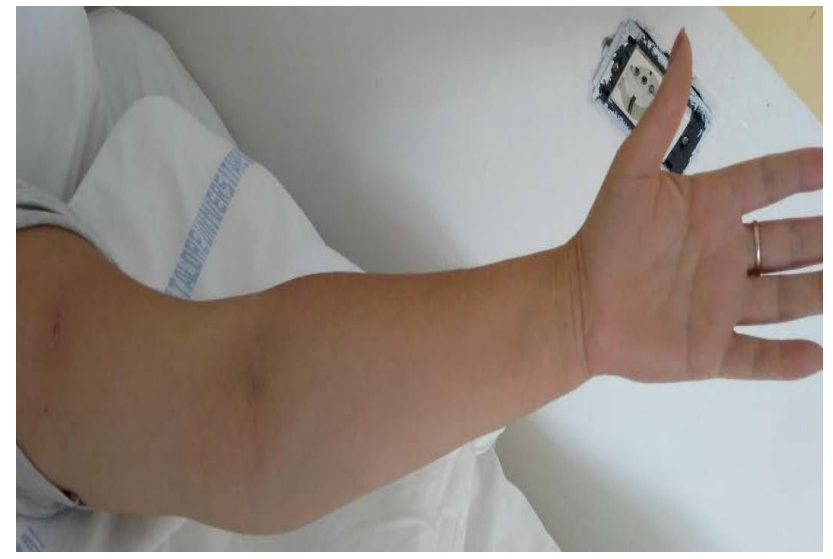

Figure 1. Black eschar in the region of the left arm on the ninth day of illness.

$10^{3} / \mathrm{mm}^{3}$ with $82.5 \%$ neutrophils, platelets $125 \times 10^{3} / \mathrm{mm}^{3}$, erythrocytes $3.86 \times$ $10^{6} / \mathrm{mm}^{3}$, hemoglobin $10.9 \mathrm{~g} / \mathrm{dl}$; glucose $76 \mathrm{mg} / \mathrm{dl}$; urea $20 \mathrm{mg} / \mathrm{dl}$; creatinine 0.7 $\mathrm{mg} / \mathrm{dl}$; aspartate transaminase $88 \mathrm{U} / \mathrm{L}$; alanine transaminase $96 \mathrm{U} / \mathrm{L}$; gamma-glutamyl transpeptidase $58 \mathrm{U} / \mathrm{L}$; lactic dehydrogenase $375 \mathrm{U} / \mathrm{L}$; bilirubin 0.4 $\mathrm{mg} / \mathrm{dl}$, natremia, $132 \mathrm{mmol} / \mathrm{L}$, fibrinogen $328 \mathrm{mg} / \mathrm{dl}$. Serological examination such as CMV, HIV, Toxoplasma gondii, EBV and Borrelia burgdorferi resulted negative. Proteine electrophoresis and immunological examination such as ANA, C3, C4 and FR were normal. The urinalysis resulted normal. Ocular examination showed vision acuity: OD 8/10, OS 2/10. Funduscopic examination complemented with fluorescein angiography showed: optic nerve papilla with clear contours, diffuse hemorrhages in the contest off retinal vein thrombosis, white retinal lesions, vascular sheathing and macular cystoids edema (Figure 2 and Figure 3).

A blood sample taken on the second day admission revealed the presence of ELISA anti Ricketsia Typhi IgM, 2.11 and absence of anti Ricketsia Typhi IgG, 


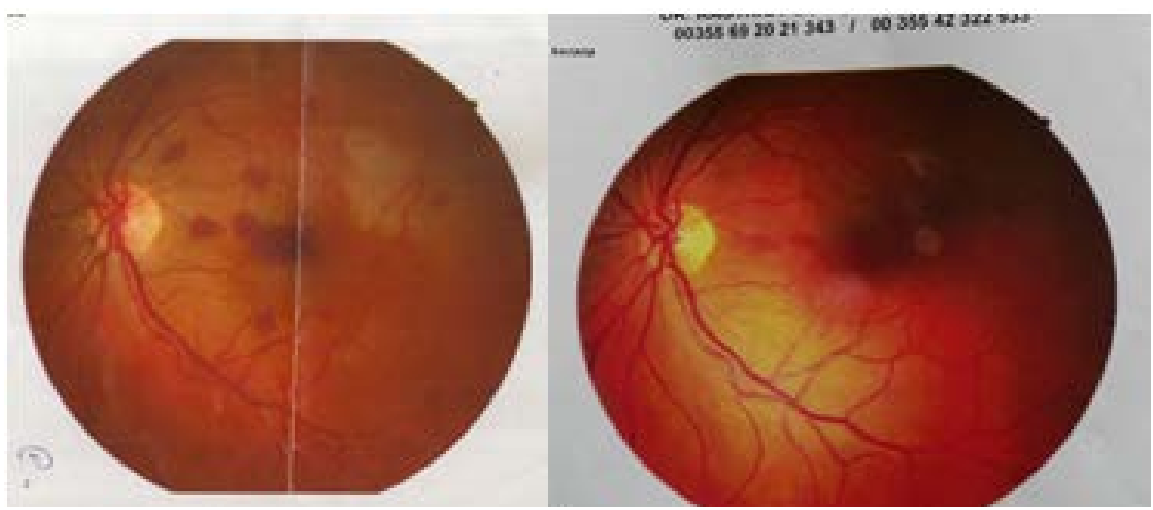

Figure 2. On the left-Diffuse hemorrhages, vascular sheathing and white retinal lesions on the first day of hospitalization. On the right-Macular hemorrhage, vascular sheathing and white retinal lesions on the thirteenth day of the hospitalization. There is a significant difference, because there are less hemorrhages.

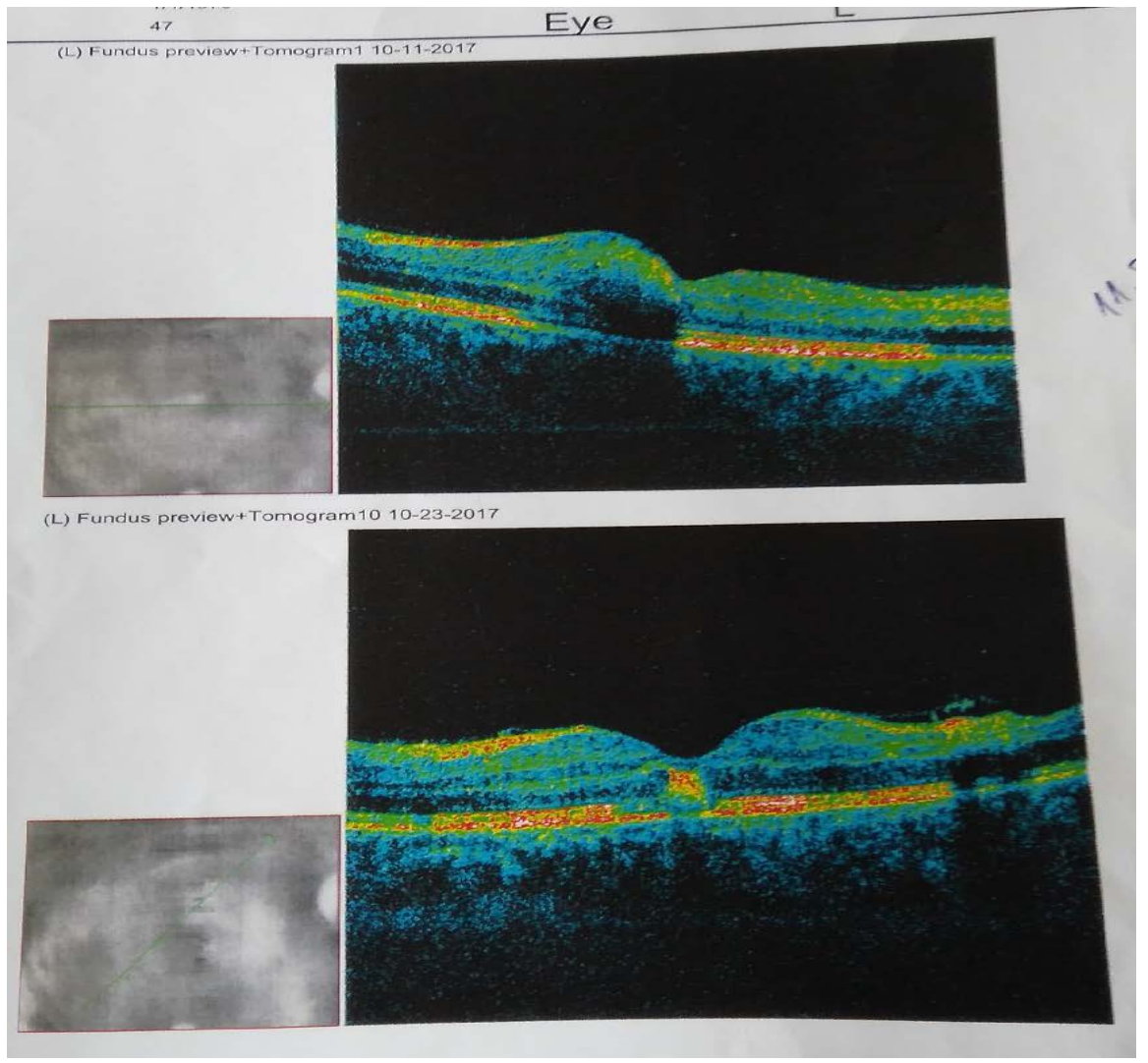

Figure 3. Macular cystoid edema on the first day of hospitalization and after on the thirteenth day. There is a significant difference, showing the positive results of treatment.

0.7 to $R$. conorii. Weil -Felix Ox-19, 1: 640. A second blood sample taken 14 days later showed a threefold rise in ELISA anti Ricketsia Typhi IgM, 14.5 and IgG 2.46 to $R$. conorii.

The patient was treated with oral Doxycycline (100 mg every $12 \mathrm{~h}$ ) for 10 days. During the hospital stay the patient showed cutaneous mycoses, presented in Figure 4 (microscopic examination showed michelle filaments). She was 


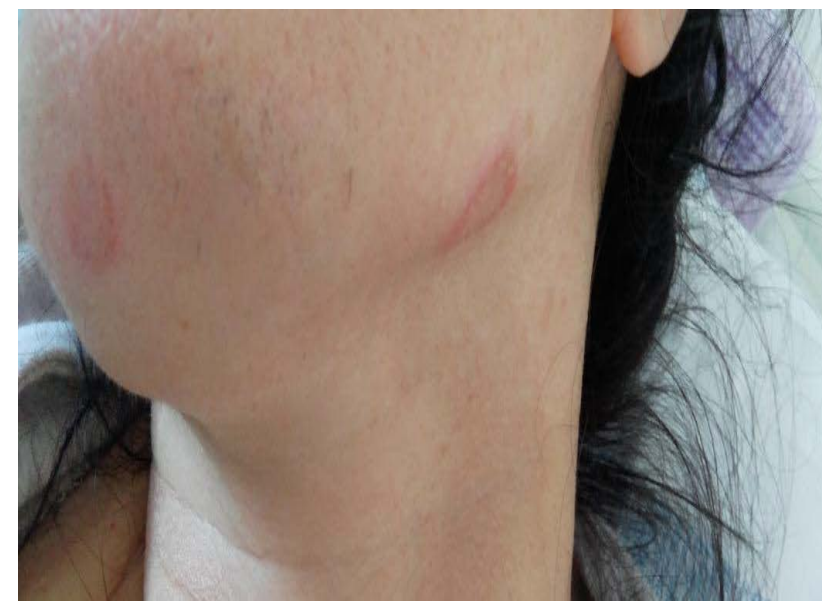

Figure 4. Cutaneous mycoses which appeared on the eleventh day of the disease.

discharged from the hospital after 15 days in good clinical conditions to be followed up by the ophthalmologist. The patient was followed for 16 weeks by ophthalmologist and specialist of infectious disease.

\section{Discussion}

In Albania there are three causative group of Ricketsie: Murine Typho, Mediterranean spotted fever and Q Fever. In a study presented from our clinic, cases with Mediterranean spotted fever consisted in $24.75 \%$ of rickettsia [9].

The patient came from Scodra. It is the largest city in northern Albania, lying near latitude $42^{\circ} 4^{\prime} \mathrm{N}$, and longitude $19^{\circ} 31^{\prime} \mathrm{E}$. According to the Köppen climate classification, Scodra experiences Mediterranean climate, which is almost wet enough in July to be a humid subtropical climate, with continental influences. The average yearly temperature varies from $14.5^{\circ} \mathrm{C}\left(58.1^{\circ} \mathrm{F}\right)$ to $16.8^{\circ} \mathrm{C}\left(62.2^{\circ} \mathrm{F}\right)$. The average yearly precipitation is about 1700 millimeters (66.9 in), which makes the area one of the wettest in Europe.

The onset of the disease in our patient was sudden. The onset is sudden in about $50 \%$ of cases. Our patient was 41 years old. According to Mouffok et al, the mean age was $38.1 \pm 2.7$ years [10]. The incubation time of our patient was 6 days. Pinna et al. reported a time of incubation of 5 - 7 days [3]. Our case showed the symptoms during autumn. This seasonal preference of symptoms is also described in the literature. However, the disease is endemic during the spring and summer in most of the regions bordering on the Mediterranean and Black seas [11]. She had contact with dogs. Contact with domestic animals is seen in $76 \%$ of patients [12]. The clinical signs and symptoms of our patient included fever (up to $40^{\circ} \mathrm{C}$ ), headache, chills, myalgias, arthralgias, malaise, anorexia, conjunctivitis, pharyngitis, and a maculopapular rash manifested after the systemic symptoms. The same clinical signs are seen also in other colleagues review [13]. She manifested hepatosplenomegaly, mild hepatitis and mild pulmonary involvement. In the literature is seen evidence of hyponatremia up to $70.5 \%$ 
of the patients, which was also seen in our case [14]. Anemia and thrombocytopenia were biological abnormalities.

Parinaud's oculoglandular syndrome, corneal ulcers, uveitis, retinal vasculitis, endophthalmitis, and anterior ischemic optic neuropathy have also been described [8].

Our patient showed thrombosis of the left central retinal vein. Retinal vascular lesion of our patient showed diffuse vascular sheathing. She was also explored for cardiovascular disease, diabetes, and glaucoma. Weil-Felix is an agglutination test for the diagnosis of rickettsial infections. It was described in 1916. The Weil Felix test suffers from poor sensitivity and specificity, with a recent study showing an overall sensitivity as low as 33\% and specificity of $46 \%$ [14]. Weil Felix Titer lacks high sensitivity and specificity but serves as an inexpensive screening test for rickettsial diseases. Weil-Felix titers more than 1:80 are considered significant for a presumptive diagnosis of rickettsiosis [15]. ELISA techniques, particularly immunoglobulin $\mathrm{M}(\operatorname{IgM})$ capture assays are probably the most sensitive tests available for rickettsial diagnosis. Presence of IgM and IgG and/or an increase to 4 times the size in the IgG titer is considered evidence of infection [16]. This growth was seen in our case as well. The treatment of choice is doxycycline, since it is effective and achieves good intracellular levels [9]. However, other medications such as Ciprofloxacin or Azithromycin may be used [10]. Early start of therapy may shorten the course of the disease and prevent complications [17]. The treatment of our case is oral doxycycline $200 \mathrm{mg}$ daily for 14 days. She was discharged from the hospital in good clinical conditions. MSF has been considered a mild disease. Thus, mortality rates of $3.2 \%$ have been reported in Algeria in 2004, 5.6\% in France in 2003, and 32.3\% in hospitalized patients in Portugal in 1997, where it was found that the risk of fatal outcome was significantly higher in those who presented with diabetes, vomiting, dehydration and uraemia [10].

\section{Conclusions}

This case was special, so we tried to mark it. Particular importance lies in the fact that between a considerable number of rickettsiosis cases presented in our infectious service disease, this manifested more complicity for us.

Thrombosis of the left central retinal vein is a serious complication of Mediterranean spotted fever.

Posterior segment changes in a patient with febrile syndromes with thrombocytopenia and/or skin rash living in or returning from a specific endemic area, especially during the spring or summer, strongly suggest $R$. conorii infection.

\section{References}

[1] Rovery, C., Brouqui, P. and Raoult, D. (2008) Questions on Mediterranean Spotted Fever a Century after Its Discovery. Emerging Infectious Diseases, 14, 1360-1367. https://doi.org/10.3201/eid1409.071133

[2] Beselga, D., Campos, A., Castro, M., et al. (2014) A Rare Case of Retinal Artery Oc- 
clusion in the Context of Mediterranean Spotted Fever. Case Reports in Ophthalmology, 5, 22-27. https://doi.org/10.1159/000358248

[3] Pinna, A. (2009) Ocular Manifestations of Rickettsiosis: 1. Mediterranean Spotted Fever: Laboratory Analysis and Case Reports. International Journal of Medical Sciences, 6, 126-127. https://doi.org/10.7150/ijms.6.126

[4] Khairallah, M., Ladjimi, A., Chakroun, M., Messaoud, R., et al. (2004) Posterior Segment Manifestations of Rickettsia conorii Infection. American Academy of Ophthalmology, 111, 529-534. https://doi.org/10.1016/j.ophtha.2003.04.012

[5] Olta, M., Tsujikawa, A., Kita, M., et al. (2008) Integrity of Foveal Photoreceptor Layer in Central Retinal Vein Occlusion. Retina, 28, 1502-1508. https://doi.org/10.1097/IAE.0b013e3181840b3c

[6] Cohn, Z.A. (1960) Relation of Cell Metabolism to Infection with Rickettsial and Bacterial Agents. Bacteriological Reviews, 24, 96-105.

[7] Walker, D.H. (2007) Rickettsiae and Rickettsial Infections: The Current State of Knowledge. Clinical Infectious Diseases, 45, S39-S44.

https://doi.org/10.1086/518145

[8] Khairallah, M., Jelliti, B. and Jenzeri, S. (2009) Emergent Infectious Uveitis. Middle East African Journal of Ophthalmology, 16, 225-238.

[9] Çomo, N., Muço, E., Kraja, D., et al. (2008) Overlook on Epidemiology and Causative Agents of Ricketsia in Adults in Albania. International Journal of Infectious Diseases, 12, 455. https://doi.org/10.1016/j.ijid.2008.05.1204

[10] Mouffok, N., Parola, P., Lepidi, H. and Raoult, D. (2009) Mediterranean Spotted Fever in Algeria-New Trends. International Journal of Infectious Diseases, 13, 227-235. https://doi.org/10.1016/j.ijid.2008.06.035

[11] Kreuzpaintner, G. and Tischendorf, F.W. (2001) Fever and Exanthema after Trip to the Mediterranean Area-Mediterranean Spotted Fever (Boutonneuse Fever). Deutsche Medizinische Wochenschrift, 126, 523-526. https://doi.org/10.1055/s-2001-13290

[12] Mert, A., Ozaras, R., Tabak, F., Bilir, M. and Ozturk, R. (2006) Mediterranean Spotted Fever: A Review of Fifteen Cases. The Journal of Dermatology, 33, 103-107. https://doi.org/10.1111/j.1346-8138.2006.00021.x

[13] Leone, S., De Marco, M., Ghirga, P., Nicastri, E., Lazzari, R. and Narciso, P. (2008) Retinopathy in Rickettsia conorii Infection: Case Report in an Immunocompetent Host. Infection, 36, 384-386. https://doi.org/10.1007/s15010-007-6291-9

[14] Agahan, A.L., Torres, J., Fuentes-Páez, G., Martínez-Osorio, H., Orduña, A. and Calonge, M. (2011) Intraocular Inflammation as the main manifestation of Rickettsia conorii Infection. Clinical Ophthalmology, 5, 1401-1407. https://doi.org/10.2147/OPTH.S21257

[15] Kularatne, S.A.M. and Gawarammana, I.B. (2009) Validity of the Weil-Felix Test in the Diagnosis of Acute Rickettsial Infections in Sri Lanca. Transactions of the Royal Society of Tropical Medicine and Hygiene, 103, 423-424. https://doi.org/10.1016/j.trstmh.2008.11.020

[16] Ajantha, G.S., Patil, S.S., Chitharagi, V.B. and Kulkarni, R.D. (2013) Rickettsiosis: A Cause of Acute Febrile Illness and Value of Weil-Felix Test. Indian Journal of Public Health, 57, 182-183. https://doi.org/10.4103/0019-557X.119817

[17] Rathi, N. and Rathi, A. (2010) Rickettsial Infections: Indian Perspective. Indian Pediatrics, 47, 157-164. https://doi.org/10.1007/s13312-010-0024-3 